\title{
CONTRIBUTORS
}

Rishikeshab Raj Regmi, Professor; Ph.D. (Anthropology)

Kailash Pyakuryal, Professor; Ph.D. (Sociology)

Padam Lal Devkota, Lecturer; Ph.D. (Anthropology)

Laya Prasad Uprety, Lecturer; (Ph.D. Student in Anthropology)

Binod Pokharel, Lecturer; M.A. (Anthropology)

Youba Raj Luintel, Lecturer; M.A. (Sociology), M.S.

(Gender Studies)

Samira Luitel, Lecturer; Ph. D. (Sociology)

Dhirendra B. Parajuli, Assistant Lecturer; (Sociology)

Philip Tanner, Development Expert; Ph.D.

\section{ANTHROPOLOGICAL INSIGHTS IN THE DELIVERY OF HEALTH SERVICES IN NEPAL}

Dr. Rishikeshab Raj Regmi

\section{Introduction}

Indigenous practitioners like herbalists and spiritualists used to practice traditional medical methods until 1950 in Nepal. A multiplicity of medical traditions are found among the various caste/ethnic communities of Nepal. Since Nepal is a multi-ethnic and multi-cultural country, there is a variety of cultural differences and similarities in primary health care practices. Beliefs, concepts and opinions are different among different communities. Concepts of health and hygiene, disease and illness also differ from culture to culture.

His Majesty's Government of Nepal had the policy to provide good health services to the people of Nepal by 2000 A.D. There is a proliferation of foreign and development programs on health care system. Many INGOs and NGOs are working under various health activities to fulfil the aspirations of about 21.5 million population of Nepal. But despite their efforts, no improvement on the quality of life of the people is noticed.

Health has always been a major concern of community development. It is a basic requirement not only for the fulfillment of people's aspirations but also for the enjoyment of the people for a better quality of life.

- Dr. Regmi is the Professor in Anthropology and Head of the Central Department of Sociology and Anthropology, Tribhuvan University, Kirtipur, Kathmandu.

The author is thankful to Prof. Kailash Nath Pyakuryal for his comments and suggestions to finalize this paper. 
The accessibility and availability of alternative curative and preventive measures of health care are the prerequisites to change the traditional health beliefs and behaviour of the people. The rural people go to the faith healers because they are the only persons available to help them in the time of ailments. The health posts in many parts of the country are not functioning properly. There are no doctors, no nurses and no medicines available in many remote health posts and sub-health posts. Therefore, there is a need to improve primary health care (PHC) in several rural areas and make available the modern methods of health care. Attempts should be made to bring changes in the people's health concept and health behaviour through persuasion. In this direction anthropological research outputs could be of immense help. The changing of attitude and behaviour of the people is not a simple task where many socio-cultural elements are intermingled. Medical pluralism is found among the practitioners of health care system. Even the people with a good economic status and education and belief in modern medicine use alternative traditional systems of healing, when the modern medicine fails to help them.

\section{Research Need}

General researchers in Nepal who are not accustomed with anthropological methods and the implications of sociocultural factors and local languages have given some discrepancies in their use of data. It is because respondents give one answer to the survey interviewees and it is the interviewer's error. Therefore, cross-checking of data obtained from survey is also useful and essential. Now-a-days, there are few studies done on ethnomedical aspects of rural and ethnic people. But for an in-depth understanding of the problems and biocultural or ecological process that affect health, holistic and contextual systematic studies are necessary. It is now clearly established that while the need for economic growth is imperative, no less is the need to obviate indiscreet assult on environment that affects adversely our life and living. The need for environmental protection being unquestionable and non-negotiable, development activities must not be allowed to outstrip the assimilative capacity of our ecosystem as well as culture. Contemporary scruting of our concept about health is needed here.

The constitution of WHO describes "health" as "a state of complete physical, mental and social well being and not merely the absence of disease or infirmity". But the definition of health still appears to be less than satisfactory, and its measurement in consequences lacks precision. Not infrequently a clear line of demarcation between health and diseases is readily recognisable and transition from one to another occurs imperceptibly.

Factors determining the status of health or disease are susceptible to changes, induced by a wide variety of circumstances, endogenous and exogenous. Candidates to be designated as healthy or diseased on the other hand, are regulated by a host of factors, genotypic and phenotypic, disclosed and undisclosed, and handle the disease producing processes or agents in a manner not too predictable. Defence mechanism is acquired in these candidates; their character, activation in response to the external stimuli are not always amenable to prior estimation. Disease attributable to ineffective agents, bacteria, parasites, viruses, fungi etc. depend on a complex succession of events before they attain the level of criminal recognition as disease entities in a given individual. The abundance distribution and availability of ineffective agents in nature are governed by a wide range of environmental factors too. Exposure of individuals to these agents, its extent and frequency are conditioned by their socio-economic status, environmental sanitation, health education, social, cultural and religious practices and occupational pursuits.

Classical epidemiologists generally try to explain why and how a disease occurs in an area. But very few attempts have been made to understand why and how the disease fails to occur in an area, where opportunities for transmission of infection are readily available. Therefore, the problem should be studied by means of multi-disciplinary ways. Every culture, irrespective of its simplicity and complexity has its own notion regarding health and health seeking behaviour, and this is often referred to as 
"Health culture". It is an integral component of the overall culture of the community. The health of any community, by and large, is a function of the interaction between socio-culture and socio-biological practices, the genetic attributes and the environmental conditions. The widely varying prevalent health practices, use of indigenous herbal drugs, taboos and superstitions are also responsible for determining the health behaviour and health status of the different ethnic groups and other communities. Many studies done by several anthropologists in Nepal, India and other developing countries reveal that socio-economic factors, socio-cultural variants like nutritional practices (food habits) are interrelated with sociobiological norms such as mating pattern, preferential alliances, age at marriage, etc., have tremendous impact on the fertility and morbidity pattern. The impact of environment and genetic factors are further additive one which complicate the situation. Some of the studies done by some anthropologists also reveal that non-availability of safe drinking water, proper sanitation and hygiene coupled with primitive health practices breed a number of diseases leading to higher mortality and morbidity rates. It is thus apparent that health is not the exclusive domain of medical sciences. It needs a co-ordination between social scientists and medical practitioners to deal effectively in both prevention and cure of diseases. As a matter of fact, more anthropological studies and sociological studies covering the different aspects of primary health care are urgently needed to understand some of the realities of health problems, particularly of rural societies. The importance of socio-economic and cultural factors in health and disease and their implication on modern medicine and public health programs can be understood only when both medical professions and social scientists collaborate with one another.

\section{Development and Change}

There has been a perceptible change in recent years regarding the focus of development polices and priorities. In Nepal, development goals are no longer defined in terms of economic growth exclusively but between the development factors required for the well-being of the people. The vital link between development process and health is being increasingly recognised and an attempt is made to reformulate policies, and programs accordingly. Investment for better health is not viewed merely as a social service, but as an investment in human resource development, contributing significantly to the process of development.

Exposure to disease producing organisms, deficiency of certain micronutrients (such as iron, vitamin $\mathrm{A}$, calcium and iodine) as well as the inadequate intake of calories and proteins remain important reasons for the lack of better health. Environmental factors are barriers in achieving better health, It is estimated that only less than 56 percent of Nepal's population have access to potable water and only 3 percent have basic sanitation facilities. There are conditions compounded by cultural, taboos and ignorance. For example, in Hindu and Buddhist culture of Nepal, abortion is, by explicit dominant values, considered a great religious sin. Many women in rural Nepal are reluctant to discuss family planning and abortion. Sexual activity is surrounded with notions of ritual pollution, strict privacy and an atmosphere of utmost reservation. Pregnant women in rural parts of Nepal are not given extra calories and proteins they require because of the belief that increased food intake during pregnancy results in larger babies culminating in difficult labour. In certain parts of rural Nepal infants are not generally given water to drink. Consequently, dehydration following diarrhoea claims many lives which could have, otherwise, been saved through proper dehydration. Other critical factors influencing health status of the communities are the quality and quantity of health services, including curative medical care, as well as preventive promotive and rehabilitative services. Availability of these facilities and their accessibilitygeographic, social and economic have an important role of particular relevance to health in the status of women that they enjoy within the home and community. This gives them the liberty to decide important family issues with health consequences-how much of the family income should be spent on food, when and where to take the child for treatment but unfortunately in Nepal women are less educated and are more 
bounded by religion and cultural values. Changes in the attitudes are very slow and need of women's education is very high.

\section{Health for all by 2000 A. D. on Primary HealthCare}

It is not uncommon to hear health personnel, irrespective of the capacity in which they are involved, or at any level of service delivery, dismiss. "Health for all by 2000 A. D. and primary health care" are as a 'jargon'. Perhaps, this stems from the definition of health which is not merely the absence of disease, but a state of positive well-being on one hand, and the practical impossibility to ensure the absence of disease on other. "Primary Health Care" is interpreted in more than one way. To some, it means only "first contact care" - which, then, would imply a conceptual frames for health planning and health service delivery which defines facilities to be provided to people in different geographic regions, when they require it. It also implies the provision of referral services for those who need more intensive health care. In Nepal, "Primary Health Care", is an approach and a philosophy for planning organising and delivery of health services. It is based on certain concepts and principles, such as accessibility (geographic, economic and social) of services as close to homes of people as possible, continued availability, provision of all components of basic health services, providing referral services at secondary and tertiary levels for those who require intensive care, reaching vulnerable groups (such as mothers, children, those socially and economically under privileged), integrated development to ensure maximal impact of various development programs and involvement of the community in healthcare.

These concepts and principles require translation into policy and program objectives. Further, resource allocation has also to be accordingly made, if these objectives have to be achieved. There is an urgent need to define the facilities (in terms of categories of manpower, their skill, diagnostic and therapeutic facilities, equipment drugs and supplies etc.), that needed to be provided at divergent levels, in order to institute streamlined referral services and avoid duplication of effort.
Studies have shown that there is paradoxical under-utilization of existing resources, in a situation where there is inadequate coverage by the health infrastructure.

There is a need to acquire managerial skills by medical and paramedical workers. The changes in "system elements" for incorporating better management practices have to be identified and instituted, if management of health service is to improve. Supervisor practices may be enlarged to include guidance and facilitation and also concentrate on qualitative aspects of health care. Another aspect and a philosophy for planning, organising and delivery of health services.

\section{Research}

Research in health includes a wide range from fundamental laboratory studies, clinical and community trials to health system research. Research in health systems may improve the efficiency of existing health services, generate factual information for decision-making and provide a base for objective health planning and programming. Research in health systems includes the assessment of health needs, and studies the production and distribution of resources for health care, the organisation of these resources, their management and economic support as well as the actual delivery of services. The services must be organised to provide adequate care as close to people, as possible, and also simultaneously develop system to ensure utilisation of services at each level. This necessitates an enquiry into (a) what quantum and range of services are to be provided at primary, secondary and tertiary levels (village, Ilaka and district levels) (b) what facilities and commodities will be required at different levels to support the defined services (c) what human resource development polices and programs and institutional capacity must one has to achieve (d) to develop mechanisms to ensure community participation and support in planning and management, as well as perhaps the rendering of certain service.

The need for researches in health related problems are increasing. An effort should be made in Nepal to develop a meaningful Management Information System for monitoring the health care programs. Several researches should be carried out 
(a) to streamline the collection procedure and reduce the load on workers (b) to evolve a mechanism of feed-back to various levels of health personnel (c) collect information which may be used for planning and monitoring services and (d) to relate it to services provided to the population.

Other important areas for research include the study of tropical diseases, fertility regulation and infertility, cardiovascular diseases, cancer diarrhoeal immunity and vaccine development, mental health and malnutrition. Most research efforts to day require multidisciplinary expertise and collaborative effort. Research costs have increased. Scientists are not sure of the continued availability of funds. There is a shortage of trained manpower for research. What is required is a purposeful balance between fundamental and applied research.

\section{Community Involvement for Health Care}

It is increasingly felt that for sustainable improvements in the quality of life of the people, community awareness and participation have pivotal and enduring role. Several contemporary, well-intentioned development programs have brought only transient changes. Some of these unsuccessful outcomes are attributable to the imposition of programs without adequate understanding and recognition of community process. The entire effort towards health care should endeavour to build on what the communities have and 'adopt' modern medical and technological advances for use by people not merely undertake programs which people must 'adopt'.

If the greatest results are to be achieved in terms of coverage, effectiveness, and efficiencies, we must encourage at grass-roots, extensive health related activities, by the people, for the people, as self-help effort. This primary health care approach should require relatively little support from outside sources. The people should be free to organise for themselves as best as they can, with appropriate encouragement from the national health authorities. Undertakings like that of village maternity centres, village pharmacies, Village Development Committee (VDC) health posts, VDC cleanliness campaigning by village people could play a leading role. Mothers, women's organisation, co- operatives, youth and village actions group can be deeply involved in the health of the people. Community participation for health care theoretically requires the promotion and inculcation of a value system which is based on mutual concern for members in the community. Villages in Nepal are not homogenous entities (where people are aligned according to caste/ethnic and kinship groups) and efforts to organise people must take cognizance of this feature. Who is to organise who, for what, remains the central point. The critical operational aspect for promoting community participation is the identification of areas where people can participate, and what can be done by whom. The mechanism for community involvement have to be developed in accordance with their resource and culture.

\section{Information, Education and Communication}

The process of self-learning and the demystification of medicine are key factors in building up the capacity of individuals and communities to look after some of their own health needs. With the advent of new channels for communication and increase in the out-reach of media, one of the most important issue is designing and implementing a relevant and comprehensive information, education and communication strategy for health. Information should include the following:

(a) Etiological and causative aspects of disease, especially those of public health importance.

(b) Health related activities which may be instituted by people themselves in relation to this, and

(c) Existing health care facilities to promote better utilization.

In addition, both formal and non-formal education may also be promoted. Appropriate technology, both hardware and software component, should equally be used. Several institutions are involved in research culminating in the incorporation of less costly and more feasible ways in health delivery services.

\section{Anthropology as a Tool}

For every scientific concept that appears in our theoretical statements there are likely to be a number of 
alternative procedures available for observing or operationalizing the relevant phenomena. The anthropological holistic approach is applied in the study of particular institutions. This is the principle of multimeasurement research. Such studies or researches in Nepal have been done on the level of illness and primary health care. Qualitative in-depth study has helped immensely in many researches along with quantitative technique.

In order to make intensive observation field-work method could be of great useful in different ecological zones of Nepal, where day to day activities are practiced according to the traditional medicine as well as with the modern allopathy methods. Therefore, anthropological field workers need to have a number of different research tools in their "field kit" unlike the situation in the pure science. Unlike the situation in the pure science research tools in social anthropology involves relatively in the way of "hardware" and gadgetry but require great sensitivity and self awareness on part of the researcher. The field worker is his own principle research instrument, and the various methods of investigation are alternative techniques for objectifying and standardizing the field-worker's perception.

For understanding the culture factors inhibiting the development of awareness of rural people in Nepal, every fileworker should be constantly alert in/on the possibilities of developing new modes of observation to supplement the standard items. In the context of Nepal, a corollary of this statement as that in practically in every instance of field research the techniques employed whether questionnaires, modes of information interviewing - must be adopted by the field worker to the requirements of the local cultural context. However, there are no ready made instruments. Researcher must be very careful in his observation.

At present, a growing number of social anthropologists involved in "traditional" research have turned to health related and development issues that the culture of the development should become a new area of anthropological inquiry is argued by anthropologist Judith Justice. Her book about Nepal, entitled, Policies, Plans and People, focuses on the integrated community health program which was gradually transformed in primary health care. Central to this book is the question : "How comes that information on socio-cultural "realities" is generally not used in planning health program ?" She argues that bureaucracy in Nepal has not understood the role of social scientist, especially the social anthropologist. Usually planners have preconceived notions, impressions and misunderstandings about anthropologist. They think that anthropologists are interested in studying only traditional medical practices and practitioners. But many anthropologist share with planners an interest in providing effective health care within a cultural milieu and solving the problems faced by rural health workers. There are two examples of the anthropological works done in Nepal which cast more light upon the issue of how to collect information about local societies.

Linda Stone (1986) also inquires into primary health care (PHC). She shows that there is a gap between written intentions (that contain vague motions) and the actual procedures. Though her project emphasised "Community Participation", the researcher was hardly happy and was doubtful whether her aim was really achieved. She argued that the project encountered problems due to three reasons in Nepal.

1. PHC fails to appreciate villager's values and their perceived needs. In particular, PHC is organized primarily to provide health education, whereas villagers value modern curative services and feel little need for new heath knowledge.

2. PHC views rural Nepali culture only pejoratively as a barrier to health education. Alternatively, local cultural beliefs, usage's and practices should be viewed as resource to facilitate dissemination and acceptance of modern health knowledge.

3. In attempting to incorporate Nepal's traditional medical practitioners into the program, primary health care has mistakenly assumed that rural clients passively believe and obey traditional practitioners. In fact, clients play active roles and are themselves in controls of the therapeutic process. 
Linda stone indicates that very little is known to the donor side about people's actual knowledge, perceptions and attitudes. Burghart (1988) inquires into the cultural knowledge of hygiene and sanitation that he sees as the basis for health development in Nepal. He concentrates mainly on the complex issue of "water" : on the criteria people use to evaluate drinking water ; classification of water sources ; forms of domestic storage of water, indigenous methods of water sources; forms of domestic storage of water, indigenous methods of water treatment and knowledge of water related diseases. While discussing the adequacy of local knowledge of hygiene and health, Burghart examines the notion of "culture" that guides developmental interventions. While addressing the problem of getting planners to translate their concerns on to the understanding of local people, he stresses that policies cannot be successfully implemented and taken up by a people if they don't acquire positive meaning in terms of their local culture. These factors necessitate the use of key methodological aspects of holistic paradigm of anthropology.

\section{Conclusions}

Most of the participatory research practices in Nepal have mistakenly concentrated on measuring tangible goods rather than helping people in the transformation process to cerate their own institutions and ideas. This has served ill to the people. With the goal of improving the quality of life and fighting against mass poverty, many rural development strategies including PHC have been implemented in Nepal. Nepal has tried many development models, both capitalistic and socialistic, borrowed from many countries, but development experiences have not shown increase in the quality of life, increased economic opportunity and increased public consciousness, etc. The flow of foreign aid started in 1952 have not given expected substantial benefits to people who mostly live in the remote rural villages of Nepal. They are all the more suffering from poverty, malnutrition, hunger, diseases and social injustice. People have slowly been losing their faith in development project because the programs used to be imposed upon them from government. Thus, nothing is gained, and many food qualities in Nepal society and culture are lost (Stiller, 1979).

\section{REFERENCES}

Achard, T

Primary Health Care in Hills of Nepal : Integrated Hill Development Project His Majesty's Government / SATA, Kathmandu.

Campbell, J.G

1976

Approaches to the Study of Shamanism. Wiener Vollcerkundlich Mitteilungen, Vienna.

Justice, J.

1986

Policies, Plan and People, Berkley: UCP.

Malinowaski, B

1961

Argonauts of Western Pacific, New York: Duton Press.

Stiller, L.P and Yadav, R.P.

1979

Planning for People, Kathmandu: Sahyogi Press.

Stone, L.

1986

"Concepts of Illness and Curing in Central Nepal Village", Contribution to the Nepalese Studies, No. 3, Kathmandu: CNAS. 